\title{
An Investigation of the General Immune Status and Specific Immune Responsiveness to Retinal-(S)-Antigen in Patients with Chronic Posterior Uveitis
}

\author{
KARIN S. FROEBEL, SYLVIA S. ARMSTRONG, ALISON M. CLIFFE, ${ }^{*}$ \\ S. J. URBANIAK, J. V. FORRESTER* \\ Aberdeen
}

\begin{abstract}
Summary
Immunological abnormalities in endogenous posterior uveitis are widely reported but difficult to verify. We have therefore studied several immunological parameters in 14 patients with chronic posterior uveitis and compared the results with 14 healthy controls. Both the general immune status and the specific immune responsiveness to retinal S-antigen have been investigated.

Results for the patient group as a whole were not significantly different from the control group. However the patients with severe eye disease $(n=4)$ had a reduced proliferative response to streptokinase-streptodornase antigen and two further individuals showed a general deficiency in functional cell mediated immunity. Circulating $T$-helper cells were marginally but not significantly reduced in patients. Responsiveness to bovine retinal S-antigen varied to a similar degree in both the patient and control groups.

These findings indicate that, although severe uveitis may be associated with functional defects in cellular immunity in certain cases, in general the measurement of immune responsiveness of peripheral blood lymphocytes is unlikely to aid in the diagnosis or management of chronic posterior uveitis.
\end{abstract}

Chronic posterior uveitis is an inflammatory disease of unknown origin which may lead to serious visual impairment. ${ }^{1}$ It may present in the context of other inflammatory diseases such as sarcoidosis and vasculitic syndromes and this has led to the suggestion that an impaired or abnormal immune responsiveness may contribute to the pathology of the disease. Further evidence for the involvement of the immune system comes from the finding that a similar form of uveitis can be induced in laboratory animals by the injection of a soluble antigen isolated from retina-the retinal S-antigen. ${ }^{2,3}$ It is suggested that an immune response to retinal $\mathrm{S}$-antigen initiates an inflammatory reaction which some individuals are unable to curtail. Support for this suggestion is provided by the fact that corticosteroids, which are known to suppress the immune system, are effective in the treatment

From: North-East of Scotland Blood Transfusion Service and * Department of Ophthalmology, Royal Infirmary, Aberdeen.

Correspondence to: Professor J. Forrester, Department of Ophthalmology, Mediçal School, Foresterhill, Aberdeen AB9 2ZD, Scotland. 
of posterior uveitis and recent reports suggest that Cyclosporin $\mathrm{A}$, which inhibits the activity of T-helper lymphocytes, is also effective. ${ }^{4}$ Several studies have indicated that uveitis patients demonstrate abnormalities of the immune system generally. ${ }^{5,6,7,8}$ In addition more recent reports have described altered cellular immune reactivity to retinal S-antigen in patients with a range of ophthalmic diseases ${ }^{9,10}$ while elevated levels of antibodies to retinal S-antigen have been demonstrated in uveitis patients, ${ }^{11,12}$ particularly those with retinal vasculitis. ${ }^{13}$ However, some of these studies have failed to note that a significnat proportion of normal individuals also appear to be sensitised to S-antigen. ${ }^{14,15} \mathrm{We}$ have therefore undertaken an investigation of patients with chronic posterior uveitis in order to determine:

(1) Whether there are any differences in lymphocyte subpopulations or cell-mediated immune function in patients that may be related to their eye disease;

(2) Whether the immune system of uveitis patients is affected by associated disease e.g. sarcoid or toxoplasmosis;

(3) Whether patients with chronic posterior uveitis are sensitised specifically to retinal S-antigen.

Cell mediated immune function was assessed by measuring the response of lymphocytes to non-specific stimulation with T-cell mitogens PHA and Concanavalin A, or specific stimulation with three different antigens:

(a) Streptokinase-streptodornase (SK-SD): an antigen associated with organisms normally present in the gut flora, and to which most of the population is naturally sensitised;

(b) purified protein derivative (PPD) from the tubercle bacillus to which most of the population has been sensitised by immunisation;

(c) bovine retinal ' $\mathrm{S}$ '-antigen.

Other reports have claimed that the number of circulating $\mathrm{T}$-helper or T-suppressor cells is abnormal in patients with eye disease. We therefore enumerated peripheral blood lymphocytes using two widely used methods each for $\mathrm{T}$ and $\mathrm{B}$ cells and staining with specific monoclonal antibodies for $\mathrm{T}$-helper and T-suppressor subpopulations.

Sensitisation to S-antigen was investigated in three ways:

(a) Levels of antibody to S-antigen in serum were measured;

(b) Stimulation of peripheral blood lymphocytes with pokeweed mitogen and examination of the supernatant for antibody to S-antigen;

(c) Measurement of the proliferation of peripheral blood lymphocytes after incubation with S-antigen.

\section{Materials and Methods \\ Subjects}

Patients with chronic posterior uveitis who were being treated at the uveoretina clinic at Aberdeen Royal Infirmary and who gave informed consent were subjects for this study. A full laboratory and clinical examination was undertaken and the severity of eye disease classified using criteria previously described: ${ }^{1}$

Category:

1. Vitreous cells plus minimal signs at pars plana (mild pars planitis),

2. Vitreous cells plus focal chorioretinal (FCR) nodules,

3. Vitreous cells plus many FCR nodules (including birdshot),

4. Vitreous cells, FCR nodules plus retinal vasculitis (RV),

5. Vitreous cells, FCR nodules, RV and macular oedema.

FCR nodules were identified as discrete small yellow or white patches in the choriocapillaris and sub-pigment epithelial space and were a common finding if carefully sought by slit-lamp fundus biomicroscopy. In addition, they characteristically showed as discrete foci of hypofluorescence in the early stages of a fluorescein angiogram with hyperfluorescence in late films. Similar appearances have been described in sympathetic ophthalmia ${ }^{16}$ which would be graded as category 2 or 3 under the present classification.

Patients with prolonged posterior uveitis due to presumed ocular toxoplasmosis (POT) or presumed ocular histoplasmosis $(\mathrm{POH})$ were classified separately, since they rarely presented evidence of retinal vasculitis and 
FCR nodules. However, they characteristically had large patches of chorioretinal inflammatory disease and active vitreous cellular infiltration. A total of 14 patients was studied, details of whom are given in Table $I$.

Apart from two patients (nos 7,12) who were receiving topical steriods, none was receiving systemic treatment at the time of testing.

A group of 14 healthy controls was tested at the same time as the patient group.

\section{Methods}

\section{Lymphocyte Separation}

Mononuclear cells were separated from heparinised whole blood using ficoll-hypaque ${ }^{17}$ and enriched for lymphocytes by incubation on plastic for 1 hour. The non-adherent cells were resuspended in 199 medium containing $20 \%$ of heat-inactivated AB serum. A full blood count and differential white cell count was performed on the same blood sample.

\section{Preparation of $S$-antigen}

$\mathrm{S}$-antigen was prepared from fresh bovine retinae as previously described. ${ }^{18}$ It was further purified on a Gilson HPLC gradient system. (Dua, Sewell and Forrester submitted) and eluted as a single peak from the column. The antigen was checked for purity by SDS polyacrylamide gel electrophoresis on the
PHAST-system (Pharmacia) according to the manufacturer's instructions, and by double immunodiffusion against polyclonal anti-S serum. ${ }^{18}$ The antigen was strongly uveitogenic when inoculated into guinea pigs with Freunds H37Ra adjuvant.

\section{Lymphocyte Transformation}

Lymphocyte transformation (proliferation) in response to T-cell mitogens PHA and Concanavalin $\mathrm{A}$, and to antigens PPD (purified protein derivative of tubercle bacillus) SK-SD (streptococcal enzymes streptokinase-streptodornase) and retinal S-antigen (S-Ag) was measured after 72 hours (mitogen cultures) or 96 hours (antigen cultures) by the uptake of $3 \mathrm{H}$-thymidine during the final 18 hours of culture. Results are expressed as the mean cpm of triplicate cultures.

\section{Lymphocyte Subpopulations}

T-lymphocytes were enumerated both by E-rosetting and by indirect immunofluorescence using monoclonal antibody to the CD 3 antigen (UCHT 1, Oxoid). T-helper and suppressor subsets were enumerated using monoclonal antibodies to the CD4 and CD8 antigens respectively (leu $3 \mathrm{a} / \mathrm{b}$ and leu $2 \mathrm{a}$ from Becton-Dickinson) as previously described. ${ }^{19}$

The E-rosette method was used as previously described ${ }^{20}$ except that slides of the

Table I Details of patients

\begin{tabular}{|c|c|c|c|c|c|}
\hline $\begin{array}{c}\text { Patient } \\
\text { No }\end{array}$ & $\mathrm{M} / \mathrm{F}$ & $\begin{array}{l}\text { Age } \\
\text { (yrs) }\end{array}$ & $\begin{array}{l}\text { Severity of eye } \\
\text { disease (category } \\
1-5 \text { : see text) }\end{array}$ & Treatment & Associated disease \\
\hline 1 & $\mathrm{~F}$ & 24 & toxoplasmosis & none & toxoplasmosis \\
\hline 2 & $\mathrm{~F}$ & 32 & 5 & none & none \\
\hline 3 & $\mathrm{~F}$ & 58 & 5 & none & none \\
\hline 4 & $\mathrm{~F}$ & 21 & 2 & none & sarcoidosis \\
\hline 5 & $\mathrm{~F}$ & 34 & 4 & none & none \\
\hline 6 & $\mathrm{~F}$ & 58 & 3 & topical steroids & none \\
\hline 7 & $\mathrm{~F}$ & 16 & 5 & none & none \\
\hline 8 & $\mathrm{~F}$ & 53 & 2 & none & sarcoidosis \\
\hline 9 & $\mathrm{~F}$ & 31 & toxoplasmosis & none & presumed ocular toxoplasmosis \\
\hline 10 & $\mathrm{~F}$ & 50 & $2+2$ & none & presumed ocular toxoplasmosis \\
\hline 11 & $\mathrm{~F}$ & 32 & 2 & none & none \\
\hline 12 & $\mathbf{F}$ & 22 & 2 & topical steroids & none \\
\hline 13 & $\mathbf{M}$ & 15 & toxoplasmosis & none & toxoplasmosis \\
\hline 14 & $\mathbf{M}$ & 37 & toxoplasmosis & none & presumed ocular toxoplasmosis \\
\hline
\end{tabular}

Patients: $n=14 ; 2 \mathrm{M} / 12 \mathrm{~F}$; mean age 32.2 years

Controls: $n=33 ; 4 \mathrm{M} / 10 \mathrm{~F}$; mean age 37.5 years 
rosetted population were made using unfixed cells and acridine orange coated coverslips.

B cells were enumerated both as surface immunoglobulin bearing cells and as cells bearing the B-cell specific antigen, CD 21.19 Results for all lymphocyte sub-populations are expressed in absolute numbers per millilitre of blood.

\section{Measurement of Antibody to S-antigen}

The antibody was measured using an ELISA technique as previously described ${ }^{15}$ For each assay a calibration curve was constructed using a standard high activity reference serum. Levels of antibody in the unknown sera were measured at a 1:100 dilution (which for most samples was on the linear part of the sigmoid calibration curve) and the results expressed as a percentage of the optical density of the reference serum at a 1:100 dilution. The levels of antibody in PWM supernatants were measured as follows: Optical density readings of a $50 \%$ solution of supernatant were found to fall most consistently on the linear part of the calibration curve.

Results are therefore expressed as the concentration of the reference serum (expressed as a percentage) which gave an equivalent optical density to a $50 \%$ solution of PWM supernatant. Readings which were outside the linear part of the curve (equivalent to a $10 \%$ solution of reference serum) are expressed as being greater than $10 \%$.

\section{Analysis of Results}

The results were analysed on the Honeywell 66/80 computer at Aberdeen University using the "Minitab" statistical package. ${ }^{21}$ The data was first examined to compare the overall results of each test for patients and controls. Subsequently the patient data was subdivided

Table II Lymphocyte proliferative responses in patients and controls

\begin{tabular}{lrr}
\hline & \multicolumn{2}{c}{$\left(\right.$ cpm: mean \pm s.e.m. $\left.\times 10^{-3}\right)$} \\
\cline { 2 - 3 } Mitogen/Antigen & Patients & Controls \\
\hline PHA $(2 \mu \mathrm{g} / \mathrm{ml})$ & $34.8 \pm 7.0$ & $38.4 \pm 3.5$ \\
Con A $(40 \mu \mathrm{g} / \mathrm{ml})$ & $25.2 \pm 2.7$ & $28.2 \pm 2.4$ \\
PPD $(40 \mu \mathrm{g} / \mathrm{ml})$ & $4.2 \pm 0.8$ & $4.8 \pm 1.1$ \\
SK-SD $(40 \mathrm{I} . \mathrm{U} . / \mathrm{ml})$ & $4.6 \pm 1.4$ & $7.3 \pm 1.5$ \\
\hline
\end{tabular}

on the basis of disease severity, or associated disease. For the purpose of statistical analysis the disease categories 1,2 and 3 , were considered together as 'mild' disease and categories 4 and 5 were considered as 'severe' disease. Data taken from patients with associated sarcoid disease were also analysed as a separate subgroup. Groups were compared using either Students t-test or an analysis of variance as appropriate.

\section{Results \\ Lymphocyte Transformation}

The mean proliferative responses to mitogens and antigens are shown in Table II.

The results for the patients and control groups were similar except for the response to SK-SD. The patient group as a whole was slightly, although not significantly reduced; the reduction was due to a minimal response in the four patients with severe disease (mean cpm: $1477 \pm 498$ compared with $7318 \pm 1476$ in the controls $(\mathrm{p}<0.01))$. Two further patients (nos. 1 and 10, both with toxoplasmosis or presumed ocular toxoplasmosis) had a virtually negative response to PPD and a reduced response to PHA and Con A. Their levels of circulating T-cells however were normal.

\section{Lymphocyte Subpopulation}

The results for patients and controls are shown in Table III. The mean number of lymphocytes of the patient group was lower than that of the control group due to a reduction in the T-helper cell subset but the differences did not reach statistical significance. Within the patient group only one individual had a level of T-helper cells that could be considered clinically significant (patient no. 8, $0.33 \times 10^{6}$ per $\mathrm{ml}$ ). This patient's transformation responses were normal, except for PPD which was low. The patient had mild eye disease but had associated sarcoidosis.

One patient (no.12) had an abnormally high number of circulating B1 cells although his other results, including his S-antibody levels were normal. In the patient group as a whole the number of B-cells determined either as B1 positive or as surface immunoglobulin positive cells was no different compared with the controls. 
Table III Number of circulating lymphocytes

No. of cells $\left(\times 10^{-6}\right)$ per ml

(meants.e.m.)

\begin{tabular}{llcc} 
& Surface antigen & Patients & Controls \\
\cline { 3 - 4 } Coll type & & $1.98 \pm 0.15$ & $2.43 \pm 0.26$ \\
Total lymphocytes & CD3 & $1.45 \pm 0.12$ & $1.84 \pm 0.26$ \\
& Sheep erythrocyte receptor (CD2) & $1.43 \pm 0.16$ & $2.00 \pm 0.24$ \\
T-helper & CD4 & $0.88 \pm 0.08$ & $1.13 \pm 0.13$ \\
T-suppressor & CD8 & $0.59 \pm 0.08$ & $0.61 \pm 0.06$ \\
B-cells & CD21 & $0.13 \pm 0.06$ & $0.10 \pm 0.01$ \\
& SIg & $0.20 \pm 0.05$ & $0.18 \pm 0.04$ \\
\hline
\end{tabular}

\section{Response to S-antigen}

Serum antibody

The serum levels of S-antibody in patients and controls are expressed in Figure 1(a) as the percentage binding to $\mathrm{S}$-antigen compared with a positive reference serum. Both the patient and control groups showed a wide range of antibody levels with median levels not significantly different (patients: $68 \%$, controls: $101 \%$ ). The levels in patients were not related to disease severity, or to associated disease, nor did they correlate with any lymphocyte subpopulation, (data not shown).

\section{S-antibody in Supernatants of pokeweed} mitogen stimulated cultures

The levels of S-antibody in the supernatants were between one and $7 \%$ of the reference serum with no difference between patient and control results (median levels: patients $3.2 \%$, controls $3.6 \%$ ). There was no correlation between S-antibody levels in PWM supernatants and serum.

\section{Proliferative Response to $S$-antigen}

The results are shown in Figure 1(b). The responses were predominantly negative for both patients and controls although three patients and one control had an elevated response. The proliferative response did not correlate with S-antibody levels either in serum or in the supernatants of PWM cultures. The three patients (nos. 11, 12 and 14) with the raised response were not remarkable in any other way. Their lymphocyte subpopulation levels were normal and they had a positive response in both mitogens and antigens.

\section{Discussion}

In this study we wished to confirm the lymphocyte abnormalities reported by other authors in patients with chronic posterior uveitis, (refs 4-14), and if present, to determine whether they were attributable to their uveitis or whether they were correlated with an associated clinical syndrome such as sarcoidosis or toxoplasmosis. Secondly we wished to establish whether the reported immune sensitivity to retinal S-antigen is specific to patients with eye disease. a)

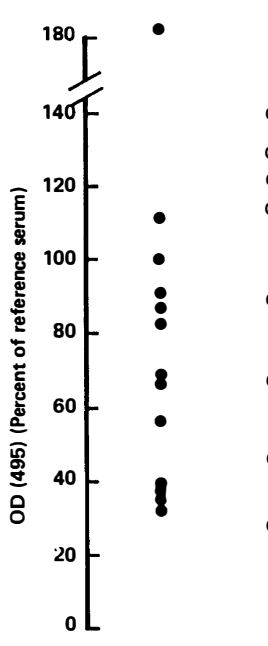

b)

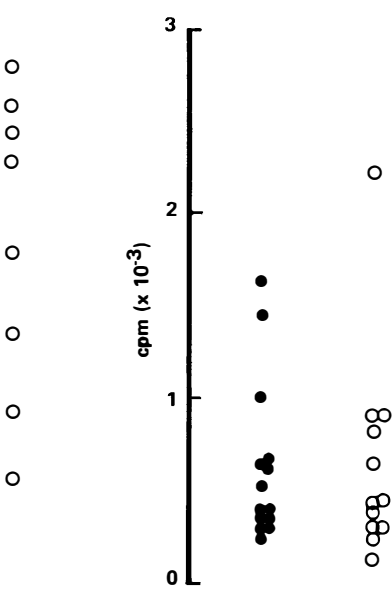

Fig. 1 Immune sensitivity to $S$-antigen in patients (O) and controls (O). (a) Serum levels of antibody to $S$-antigen. Results are recorded as the optical density at $495 \mathrm{~mm}$ of a 1:100 dilution of serum and expressed as a percentage of a reference serum. (b) Proliferative response of peripheral blood cells to $S$-antigen in vitro. Results are expressed as the mean cpm $\left(x 10^{-3}\right)$ of triplicate cultures. 
We were unable to show any overall difference in the immune status of patients compared with controls. When the patient group was subdivided into categories of severity however, a subgroup of four patients with severe eye disease (defined as retinal vasculitis with or without macular oedema) had a significantly reduced response to the environmental antigen SK-SD. One of these four and a second patient with mild (category 2) disease had generally an abnormally low response to both antigen and mitogen stimulation. The number of circulating T-cells in these patients was normal suggesting a functional defect in their cell mediated immune system. The reduced response to SK-SD antigen could be due to the loss or impairment of specific memory cells. Alternatively, reduced antigen responsiveness could be due to functional impairment of the T-cell receptor for antigens, although why the reduction is specific for SK-SD and does not extend to PPD is unclear. An alternative method of measuring T-cell activation, such as the measurement of soluble activation products: e.g. migration inhibition factor, or in vivo skin testing to a range of re-call antigens may clarify this observed defect.

In the lymphocyte subset results there was no significant difference between the patient and control groups. One patient had a slight lymphopenia which was reflected in both the T-helper and T-suppressor subsets but her functional responses were normal. We were unable to confirm the observation of Nussenblatt et al. ${ }^{7}$ that uveitis is associated with a reduced number of circulating T-cells. In their study, they found that there was no difference in lymphocyte subsets between uveitis patients and controls overall. However, they noticed that when patients with active posterior uveitis were compared with controls, there was a reduction in the T-helper/suppressor cell ratio. In the present study, all patients had active disease and they were compared with a similar number of healthy controls. The number of circulating T-helper cells was marginally reduced in all the patient groups but the reduction was not statistically significant and, apart from one individual, not clinically significant. The number of circulating T-suppressor cells was similar in patients and controls.

Wakefield et al. have reported a $76 \%$ incidence of T-lymphopenia in patients with untreated retinal vasculitis. ${ }^{22}$ We found no correlation between lymphocyte total counts or subpopulations and retinal vasculitis. The one patient with T-lymphopenia had associated sarcoidosis but no evidence of retinal vasculitis. We analysed the data further on the basis of associated disease. The patient group included two patients with associated sarcoidosis and five patients with presumed ocular toxoplasmosis or presumed ocular histoplasmosis. As mentioned above, the patient with lymphopenia also had sarcoidosis. One patient with toxoplasmosis and one with presumed ocular toxoplasmosis had reduced transformation responses to both antigens and mitogens. The other three had normal results. Thus, there is no clear association with associated disease although associated disease may be linked to immune deficiency in individuals.

Immune sensitivity to S-antigen was determined for both B-cells and T-cells. Serum antibody levels in patients varied widely from $34-185 \%$ of a reference serum. However, the healthy control group, with no history or evidence of eye disease, had essentially the same range of results (28-140\%) (Fig.1a). Similarly when B-cells were stimulated with pokeweed mitogen the range of levels of anti-S-antibody in the supernatants was similar for both patients and controls (Fig.1b).

These findings confirm two recent studies indicating that humoral reactivity to retinal S-antigen is a 'natural' phenomenon and does not correlate with disease activity. ${ }^{14,15}$ T-cell sensitivity was determined by incubating peripheral blood lymphocytes with bovine S-antigen and measuring proliferation after 96 hours. Here, too, the spread of results was similar in the patient and control groups. Cellular reactivity to retinal S-antigen in human uveitis has been reported by Nussenblatt $e t$ al. ${ }^{10,23}$ particularly in association with birdshot retinochoroidopathy. ${ }^{23}$ The present study fails to support this work. High doses of S-antigen have been shown recently to induce in vitro proliferation responses in $\mathrm{T}$ lymphocytes of uveitis patients but similar responses 
were seen in a significant percentage of healthy controls. ${ }^{24}$ The lack of detectable difference between patient and control responses to $\mathrm{S}$-antigen may in part be due to the relative insensitivity of current tests. In any circulating pool of lymphocytes, only a very small proportion of cells will be sensitised to a specific antigen, particularly if the antigen is organ specific, is in relatively low concentration, and is normally excluded from the blood stream via physiological barriers such as the blood retinal barrier. Analysis of intraocular fluids have also shown that there is considerable variation in the $\mathrm{T}$ - and $\mathrm{B}$-cell counts but that in general the proportions of each cell type reflect those of the peripheral blood, and that such tests are equally likely to be unhelpful in the diagnosis or management of the disease. ${ }^{26}$ More recently, the presence of 'activated' $T$ cells, bearing the interleukin 2 receptor, have been shown in uveitis patients ${ }^{27}$ and this may be of some relevance to disease activity.

In conclusion, our study suggests that there may be a functional deficiency in cell-mediated immunity in patients with severe eye disease. As this study was carried out at a single time point for each patient we cannot say whether the abnormality is the cause or a result of the eye disease. We and others ${ }^{25}$ have been unable to confirm previous reports of reduced $\mathrm{T}$-cells in eye disease $\mathrm{e}^{5,7,22}$ probably because of the greater attention paid to the use of adequate control populations. Although individual patients have been shown to have very marked deficiencies in their cell-mediated immune system, we conclude that the extent of the functional differences is generally too small to be useful in the diagnosis and management of individual cases using current generally available methods of investigation.

The authors wish to acknowledge the technical assistance of Gillian Stewart, Karen Hercus, Elizabeth Muckersie and Derry Campbell and the secretarial assistance of Pamela Allan. This work was supported by a grant from the Grampian Health Board.

\footnotetext{
References

${ }^{1}$ Forrester JV: Chronic intraocular inflammation. Trans Opthalmol Soc UK 1985, 104: 250-5.

${ }^{2}$ Wacker WB, Donoso LA, Kalsow LM, Yankedoo
}

JA, Organisciak DT: Experimental allergic uveitis: isolation, characterisation and localisation of a soluble uveitopathogenic antigen from bovine retina. J Immunol 1977, 119: 1949-58.

${ }^{3}$ Forrester JV, Borthwick GM, McMenamin PG: Ultrastructural pathology of S-antigen uveoretinitis. Invest Ophthal Vis Sci 1985, 26: 1281-92.

${ }^{4}$ Nussenblatt RB, Palestine AG, Chan Chi-Chao: Cyclosporin A therapy in the treatment of intraocular inflammatory disease resistant to systemic corticosteroids and cytotoxic agents. Am J Ophthalmol 1983, 96: 275-82.

${ }^{5}$ Byrom NA, Campbell MA, Hobbs JR, Dean AJ, Timlin DM, Webley M, Brewerton DA: T and B lymphocytes in patients with acute anterior uveitis and ankylosing spondylitis and their household contacts. Lancet 1979, ii: 601-3.

${ }^{6}$ Abrahams IW and Gregerson DS: Longitudinal study of serum antibody responses to bovine retinal $\mathrm{S}$-antigen in endogenous granulomatous uveitis. Br J Ophthalmol 1983, 67: 681-4.

${ }^{7}$ Nussenblatt RB, Salinas-Carmona M, Leake W, Scher I: T Lymphocyte subsets in uveitis. Am J Ophthalmol 1983, 95: 614-21.

${ }^{8}$ Forrester JV and Borthwick GM: Clinical relevance of $\mathrm{S}$ antigen induced experimental uveoretinitis. Trans Ophthalmol Soc UK 1984, 103: 497-502.

${ }^{9}$ Donoso LA, Rorke LB, Shields JA, Augsburger JJ, Brounstein S, Lahoud S: S-antigen immunoreactivity in trilateral retinoblastoma. $A m J$ Ophthalmol 1987, 103: 57-62.

${ }^{10}$ Nussenblatt RB, Gery I, Ballintine EJ, Wacker WB: Cellular immune responsiveness of uveitis patients to retinal S antigen. Am J Ophthalmol 1980, 89: 173-9.

${ }^{11}$ Gregerson DS, Abrahams IW, Thirkhill CE: Serum antibody levels of uveitis patients to bovine retinal antigens. Invest Ophthalmol Vis Sci 1981, 21: 669-80.

12 Uusitalo RJ, Stjernschantz J, Mahlberg K, Gregerson DS, Uusitalo $\mathrm{H}$, Tallberg T, Palkama A: Serum antibody level to $S$-antigen in children with chronic uveitis. Br J Ophthalmol 1985, 69: 21216.

${ }^{13}$ Dumonde DC, Kasp-Grochowska E, Graham E, Sanders MD, Faure JP, de Kozak Y, van Tuyen V: Anti-retinal autoimmunity and circulating immune complexes in patients with retinal vasculitis. Lancet 1982, ii: 787-92.

${ }^{14}$ Doekes G, Van der Gaag R, Rothova A, van Kooyk J, Broersma L, Zaal MJM, Dijkman G, Fortuin ME, Baarsma GS, Kiljstra A: Humoral and cellular immune responsiveness to human S-antigen in uveitis. Curr Eye Res 1987, 6: 909-19.

${ }^{15}$ Forrester JV, Stott D, Hercus K: Naturally occurring autoantibodies to retinal S-antigen in uveitis patients and normal healthy controls. $\mathrm{Br} J$ Ophthalmol 1989, 73: 155-9.

16 Sharp DC, Bell RA, Patterson E, Pinkerton RM: Sympathetic ophthalmia. Histopathologic and fluorescein angiographic correlation. Arch Ophtahlmol 1984, 102: 232-5. 
${ }^{17}$ Boyum A: Separation of lymphocytes and erythrocytes by centrifugation. Scand J Clin Lab Invest 1968, 20: Suppl 97.

${ }^{18}$ Borthwick GM and Forrester JV: Purification of retinal S-antigen by ion-exchange chromatography and chromatofocussing. Exp Eye Res 1983, 37: 613-25.

${ }^{19}$ Froebel K, Dickson R, Lewis D, Jasani MK, Sturrock RD: Characteristics of spontaneously proliferating mononuclear cells in rheumatoid arthritis. Ann Rheum Dis 1984, 43: 709-13.

${ }^{20}$ Urbaniak SJ, McCann MC, White AG, Barclay GR, Kay AB: Tests of immune function. In Weir DM ed. Handbook of Experimental Immunology 4th ed. Oxford Blackwell, 1986, 126: 4-5.

${ }^{21}$ Ryan, Joiner, Ryan: Minitab 2nd ed Boston Duxbury Press, 1986.

${ }^{22}$ Wakefield D, Easter J, Penny R: Immunological abnormalities in patients with untreated retinal vasculitis. Br J Ophthalmol 1986, 70: 260-5.
${ }^{23}$ Nussenblatt RB, Mittal KK, Ryan SJ, Green WR, Maumenee AE: Birdshot retinochoroidopathy associated with HLA-A29 antigen and immune responsiveness to retinal $\mathrm{S}$ antigen. $A m J$ Ophthalmol 1982, 94: 147-58.

${ }^{24}$ Hirose S, Tanaka T, Nussenblatt R, Palestine AB, Wiggert B, Redmond TM, Chader GJ, Gery I: Lymphocyte responses to retinal-specific antigens in uveitis patients and healthy controls. Curr Eye Res 1988, 7: 393-402.

${ }^{25}$ Murray PI, Dinning WJ, Rahi AHS: T-lymphocyte subpopulation in uveitis. Br J Ophthalmol 1984, 68: 746-9

${ }^{26}$ Deschennes J, Freeman WR, Char DH, Garovoy MR: Lymphocyte subpopulations in uveitis. Arch Ophthalmol 1986, 104: 233-6.

${ }^{27}$ Deschennes J, Char DH, Kalita S: Activated T Lymphocytes in uveitis. Br J Ophthamol 1988, 72: 83-7. 